This item was submitted to Loughborough's Research Repository by the author.

Items in Figshare are protected by copyright, with all rights reserved, unless otherwise indicated.

\title{
The assessment of food safety culture: An investigation of current challenges, barriers and future opportunities within the food industry
}

PLEASE CITE THE PUBLISHED VERSION

http://dx.doi.org/10.1016/j.foodcont.2016.10.061

PUBLISHER

(c) Elsevier

VERSION

AM (Accepted Manuscript)

\section{PUBLISHER STATEMENT}

This work is made available according to the conditions of the Creative Commons Attribution-NonCommercialNoDerivatives 4.0 International (CC BY-NC-ND 4.0) licence. Full details of this licence are available at: https://creativecommons.org/licenses/by-nc-nd/4.0/

\section{LICENCE}

CC BY-NC-ND 4.0

\section{REPOSITORY RECORD}

Nayak, Rounaq, and Patrick Waterson. 2016. "The Assessment of Food Safety Culture: An Investigation of Current Challenges, Barriers and Future Opportunities Within the Food Industry”. Loughborough University. https://hdl.handle.net/2134/23304. 
7

8

9

10

11

12

13

14

15

16

17

18

19

20

21

22

23

24

25

27

The Assessment of Food Safety Culture: An investigation of current challenges, barriers and future opportunities within the food industry

(1)

(1)

(1)

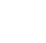

(1)

1

12

Human Factors and Complex Systems Group, Loughborough Design School, Loughborough University, Loughborough, LE11 3TU, UK

\author{
Rounaq Nayak and Patrick Waterson
}


Abstract

32 Following the 2005 E.coli O157 outbreak in the UK and the recommendations in the 33 subsequent Public Enquiry Report in 2009, the topic of food safety culture became 34 more prominent. In 2012, the United Kingdom's Food Standards Agency (FSA) commissioned a tool that enforcement officers could use to assess 'softer aspects' of risk such as safety culture, attitudes and behaviours. In the present study, we assessed the awareness of and views on safety culture in the food industry among a group of industry stakeholders (Environmental Health Officers, Food and Beverage Managers, Academics). The study also examines their attitudes towards the toolkit and ways in which it could be improved (e.g., its usability). The conclusions of the paper are that whilst there is broad support for implementing safety culture in the food industry, there are also some outstanding challenges (e.g., defining food safety culture, senior management commitment and the role played by 'micro-cultures' within food organisations). Assessing safety culture in the food industry is a realistic possibility, but needs to take account of some of the lessons which could be learnt from other industries (e.g., healthcare, rail, oil and gas) and their experiences with safety culture.

Key words: Food safety culture; Food safety culture assessment; Food safety culture toolkit

\section{Highlights}

- The food industry aims to achieve food safety by solely focusing on traditional methods.

- The food industry needs to move on from reactive methods to achieve success in a changing environment.

- Assessing safety culture in food businesses is vital and beneficial for the food industry.

- Most stakeholders are ready to adopt a proactive approach towards achieving food safety. 


\section{Introduction - safety culture}

62 It has been 30 years since the Chernobyl accident occurred in the former Soviet

63 Union. There is a general agreement in the literature (e.g., Antonsen, 2009; Edwards,

64 Davey, and Armstrong, 2013; Griffith, Livesey, and Clayton, 2010) that this disaster

65 transformed the landscape of industrial safety and gave birth to the concept of 'safety culture'. The 2002 International Nuclear Safety Group (INSAG) report concluded that poor safety culture was the leading factor that led to the accident. There are multiple definitions for safety culture. Safety culture is often used to refer to human and organisational behaviour (what people do and the way a company operates). In the context of organisational safety culture, it is defined as 'the combination of those (safety related) behaviours which either increase or decrease the risk of harm, with safe denoting protected from harm, and unsafe at high risk of harm' (Edwards et al., 2013). This subsequently became a common concern in highrisk industries (e.g., aviation - Branford, 2011; nuclear - International Atomic Energy Agency, 2002; oil and gas - Antonsen, 2009; healthcare - Waterson, 2014; transportation - Salmon et al., 2012). A group of people's behaviours (based on their beliefs, perceptions and values of safety) defines the safety culture in a workplace (Cooper, 2000; Gadd and Collins, 2002). In the last few years, safety culture has been applied within the food industry as the food industry is a complex sociotechnical system and a systems approach would be required to help adopt a proactive approach (Cassano-Piche et al., 2009; Nayak and Waterson, 2016; Vicente and Christoffersen, 2006). There is limited research in the area of food safety culture, however, the available literature suggests that it continues to grow in popularity and is being assessed within organisations (Griffith et al., 2010; Institute for Employment Studies \& Cardiff Work Environment Research Centre, 2010; Taylor, 2011).

87 1.1. Safety culture in the food industry

88 A good food safety culture is sometimes characterised as one in which employees 89 share a sense of purpose in maintaining food safety standards (Stanwell-Smith, 2013). The evidence for this can be found in a series of recent studies carried out by a range of researchers (e.g., Bona et al., 2012; Griffith, 2010; Da Cunha et al., 2014; Jespersen and Huffman 2014; MacKay et al., 2016; Samapundo et al., 2016; Taylor, 2011). All of these publications emphasise the relationship between food safety 
94 behaviours, employee training and food safety. The study carried out by Griffith et al. 95 (2010) in the UK also highlighted the presence of multiple cultures within highly regulated environments (e.g., management and shop floor plants) within a business. While the management characterized themselves as committed and responsible, this did not appear to be communicated to the different sets of workers in each plant. One of the two sites had positive attitudes towards management's commitment to safety and had greater risk awareness, whilst the other shop floor was more negative towards management. Studies carried out in other parts of the world (e.g., Sarter and Sarter, 2012; Sani and Siow, 2014; Jespersen and Huffman, 2014) show that food safety culture can be specific to each country, as each country has its own traditions and regulations. A study carried out by Griffith (2000) showed that the extent of noncompliance can also make a difference in terms of the level of associated-risk - not only does it affect quality but also has major impacts on food safety. If overlooked or ignored, it can also lead to food poisoning, bankruptcy and damage to brand identity 108 (Griffith, 2000).

109

1.1.1 The UK Food Standards Agency (FSA) toolkit

111 In January 2012, the Food Standards Agency (FSA) commissioned a toolkit which 112 was designed to help Environmental Health Officers assess the 'softer' aspects of 113 risk (e.g., safety culture, management attitudes and behaviours, compliance with 114 hygiene regulations). Development of the toolkit was undertaken by the human 115 factors consultants 'Greenstreet Berman' who carried out a review of existing food 116 safety culture research and tools. As there was no tool dedicated to assessing safety 117 culture in the food industry, Greenstreet Berman developed a new toolkit after 118 reviewing other safety culture tools that were available in the public domain (e.g., 119 from the Rail and Health Care industries) (Food Standards Agency, 2013; 120 Greenstreet Berman, 2012). Tables 1 and 2 show the core components from the 121 toolkit. Figure 1 highlights the titles of the 'elements' section of the toolkit. 
125 1.2. Study aims and objectives

126 The primary aim of this paper was to provide a better understanding of the views of a

127 group of food safety stakeholders (Environmental Health Officers, Food and 128 Beverage Managers, Academics) towards the construct of food safety culture. In 129 order to probe deeper into these views and attitudes we also carried out an 130 evaluation of the FSA approved toolkit. The specific objectives of the paper were 131 twofold:

132 1. To analyse the views towards and the challenges, barriers and opportunities in 133 adopting safety culture in the food industry;

134 2. To evaluate attitudes towards a specific toolkit that assesses food safety culture.

\section{2. Methods}

136 2.1. Participants

137 A total of 30 semi-structured interviews $(n=30)$ were carried out between January 138 and May 2016. Fifteen participants were Environmental Health Officers (EHOs) (from 139 the East Midlands region in the UK); twelve were employed as Food and Beverage 140 managers (from the East Midlands region in the UK and Europe); three were 141 academics (from the West Midlands and East Midlands regions in the UK). Two of 142 the academics also worked as part-time consultant food inspectors. Table 3 shows 143 details of participants' background and experience in the food safety industry.

147 Environmental Health Officers (EHOs) were recruited by contacting councils across 148 England; Food and Beverage Managers were recruited by contacting Universities 149 and a food business located in the Midlands of the UK. A final set of participants 150 worked as University-based Academics and also worked as either part-time EHOs or 151 consultant food safety professionals. Participants were selected on the basis that 152 they were from varying employment backgrounds (i.e. public and private sector 153 employees and Universities) in order to get diverse opinions about assessing safety 
154 culture in food businesses. We recruited EHOs and food inspectors employed by 155 food businesses (e.g., Food and Beverage managers) in order to get an insight into 156 the problems of assessing food safety culture and to assess the possibility of 157 evaluating safety culture in food businesses. Academics (all of whom were either ex158 EHOs or current consultant food inspectors) were recruited in order to get an 159 alternative (scientific) perspective of the need for safety culture in food businesses. 160 Being full-time academics, the authors found a difference in their response 161 compared to those of EHO and food inspectors. A purposive sampling strategy was 162 employed in order to ensure that there was a representative and qualified sample in 163 the various categories. Purposive sampling relies on the researcher's judgement in 164 terms of setting the criteria for selecting participants who possess specific 165 characteristics (Morse, 2004). Interviews lasted between 25 - 40 minutes and were 166 digitally recorded and transcribed.

168 2.2. Interview schedule

169 A semi-structured interview schedule was developed and reviewed by both the 170 authors. It consisted of three sections: section 1 included questions about 171 participant's experience and their area of work in the food industry; section 2 172 included questions on the current systems used to assess food safety (e.g., Food 173 Hygiene Rating Scheme, Food Safety Management System, Hazard Analysis and 174 Critical Control Points - HACCP). The final part of the interview schedule consisted 175 of questions regarding perception of food safety culture among participants. In this 176 section, questions mainly focussed on three elements: (1) safety culture; (2) food 177 safety culture; and, (3) the government approved toolkit developed to assess food 178 safety culture. Questions covering safety culture and food safety culture aimed to 179 provide a better understanding of the participants' grasp of the terms. Questions on 180 the toolkit were designed to probe further into food safety practitioner's views on the 181 practicality of using the FSA toolkit. The lead author who has had extensive training 182 on how to perform qualitative studies and conduct interviews carried out the 183 interviews. 
185 Before content analysis can begin, they need to be stored in a format that can be easily analysed. In order to do this, interviews are transcribed and coded. Coding involves summarizing transcriptions into groups in order to make comparisons easier

188 (Braun and Clarke, 2006). Each group is as similar to each other as possible and as 189 different in concepts from other groups as possible. All interviews were manually 190 transcribed into Microsoft Word documents. They were then broken down into sections according to the interview schedule in the NVivo (version 10) qualitative data analysis software package. Themes were identified from the data collected instead of trying to fit the themes into a pre-existing coding frame. This form of coding is called inductive thematic coding (Braun and Clarke, 2006) and was used to organize and describe the data set in rich detail and to identify, analyse and report patterns within the data (Flick, 2014). Table 4 highlights the coding framework that was developed by this method of coding and analysis.

Table 4 about here

200

\section{Findings}

201

\subsection{Awareness and attitudes towards safety culture}

202 Most participants were aware of the concept of safety culture and had some idea 203 about what it meant. Twenty-five out of the 30 participants felt that it was important to 204 establish and assess the culture of a food business in order to achieve the objectives 205 of producing safe food. One of the participants also mentioned reading about it during a "Level 4 food safety" training course (provided by the UK Chartered Institute of Environmental Health) and a set of case studies that helped further understand the importance of a positive safety culture:

"I think it is coming to fruition and is something that you can't ignore. It is something 210 you have to really take on board like for example the health and safety culture side of 211 things." (Environmental Health Officer)

212 In the UK, although the health and safety department encompasses food industries, 213 only the Food Standards Agency (FSA) deals with food hygiene. The health and 
214 safety departments ensure appropriate design of food machinery and health and 215 safety of the employees. Food safety is treated as separate to other aspects of 216 safety and this is an artificial separation. In order to assure optimum levels of safety, 217 the two should be combined:

218 "... we include the health and safety team as well as the food safety technical team 219 to get the best opinion on bettering safety and hence the safety culture on the factory 220 floor." (Director of Food Safety and Health and Safety)

221 "[Safety culture was] always something that was mentioned more in Health and 222 Safety circles than it was in food but it seems obvious now that there is no reason 223 why it shouldn't apply equally to food safety." (Environmental Health Officer)

224 3.1.1. Safety culture as a core and an implicit part of the business

225 All food businesses have pre-set attitudes (either positive or negative) towards food 226 safety and hygiene which they try to instil into their employees. Participants identified 227 two types of food business operators: (1) ones that prioritised profits over hygiene 228 and safety; and, (2) ones that prioritised hygiene and good practices over profits. 229 They felt that there could be a relationship between the size of the business, safety 230 culture policy and the likelihood of compliance with safety culture:

231 "It depends on the way that the business is organized. ... national businesses ... 232 have guidance from above and a culture more or less imposed on them. ... the micro 233 owner managed businesses do not have the money to spend on food safety 234 expertise and hence the culture is quite individual to those particular premises." 235 (Consultant food inspector)

236 Most Environmental Health Officers and Food and Beverage managers felt 237 assessing safety culture in a food business was something they already did during 238 routine inspections. The novel aspect of the FSC tool was that it was formalised and 239 made explicit:

240 "It is natural for EHOs to judge food businesses based on their observations, even if 241 FSC is not made mandatory. EHOs usually judge confidence in management and 242 attitudes of food businesses towards safety." (Academic) 
243 They claimed that it was their instincts and perceptions that helped them evaluate 244 safety culture 'accurately' and hence were already aware about the concept of safety 245 culture:

246 "To me it's obvious as I can judge the culture as soon as I enter the premises... 247 people with that attitude to food safety would have the same attitude to, for example, 248 using their phone while they're driving." (Health and Safety Advisor, ex-EHO)

\subsubsection{Challenges}

251 3.1.2.1. Interpretation of the meaning of 'safety culture'

252 Although most participants knew what safety culture meant, not all of them could 253 define it. There was also confusion between safety culture and safety climate. The 254 former refers to behavioural aspects (i.e. what people do) and the situational aspects 255 of the company (i.e. what the company has) and the latter refers to psychological 256 characteristics of employees (i.e. how people feel) with regard to safety within an organization (Health and Safety Executive, 2005; Mearns et al., , 2003):

"... Food safety culture to me is usually the manager's or the food business operator's focus of interest in the business and employees' perceptions (of safety practices) shared within a business ..." (Environmental Health Officer)

"There is this confusion between safety culture and safety climate which I feel needs to be cleared out. ... culture is more to do with behaviour, whereas climate is more to do with how the people feel ..." (Director of Food Safety and Health and Safety)

Not only is safety culture poorly defined, but it also has multiple dimensions linked to it, one of the dimensions being national culture. One of the participants related safety culture to employees belonging to different cultural backgrounds and having different traditional food safety practices:

272 "I think safety culture has to do with where employees are from. We have some 273 people with various traditional backgrounds and hence each one has their own safety practices based on their culture" (Head of Catering) 
277 There was concern that although employees received regular training, they would 278 'slip back' and revert to the existing culture of the business. This was seen as a 279 challenge as training might provide an employee with more knowledge, but this 280 might not be translated into action or result in safer or risk conscious behaviour. In 281 order to achieve 'continuous improvement', there would have to be encouragement 282 and support from colleagues and the work environment:

283 "I think that you can send people on training courses all you like ... but within a 284 couple of days of doing a course even if they do change what they do I think they 285 slip back in to whatever that culture is." (Environmental Health Officer)

286 There were also a few self-motivated employees who irrespective of the positive or 287 negative safety culture within the business, carried out good hygiene practices:

288 "Some people are motivated enough that they would do their work well, but an awful 289 lot of people sort of slide into whatever the culture is." (Environmental Health Officer)

290 3.1.3. Senior management commitment and the role played by national culture

291 If senior management and food business operators were too focussed on profit 292 generation and were too distanced from employees, they would not set an example 293 of a positive safety culture. In such a scenario, even the employees would follow suit:

294 "... whether they are interested in the business because of their interest in food 295 safety or whether they are interested in the business because it's going to make 296 them a lot of money. This sets the safety culture of a business, which the employees 297 follow." (Environmental Health Officer)

298 Participants felt that the workers in a business would be as committed to good 299 hygiene practices as their senior management:

300 "I think it all comes down to the [commitment of the] local management, you can get 301 businesses that are awful and businesses that are very good. Sometimes when the 302 owners of the businesses have a strong link to the business, they care more." 303 (Environmental Health Officer) 
304 Food businesses are often owned by, and employ people from various ethnic backgrounds. According to The Federation of Specialist Restaurants' market research in 2015, there were 9500 Indian restaurants and 8000 Chinese takeaways as of 2015 in the UK. If food businesses failed to instil their safety culture values in their employees, due to the differences in traditional practices, employees belonging to various nationalities would carry out food safety practices according to their traditions. The stakeholders were worried that this could have a negative impact on food safety and hygiene:

312 "[l once visited a] bakery owned by a [anonymised nationality] person ... who had 313 kept car tyres inside the bakery. He did not see any flaw with that as they did it all 314 the time [in their home country]. ... if you go to a bakery [owned by an anonymised nationality], this won't be the case as ... their culture dictates cleanliness."

316 (Academic)

317 3.2. Attitudes towards the Food Safety Culture toolkit

\subsubsection{Positive responses to the toolkit}

319 Twenty-one participants out of the thirty preferred only certain aspects of the toolkit 320 (e.g., use of matrices to segregate businesses, use of different colours to separate 321 various categories, level 1 in the toolkit and culture definitions). Four of the 322 stakeholders felt that Level 1 of the toolkit was very precise and detailed and would 323 help accurately categorize food businesses:

324 “... with level 1 I think it's fairly good at describing different situations. So if you go to 325 a place it doesn't take too long to determine which category it's going to fall into." 326 (Environmental Health Officer)

They also felt that the culture definitions that were provided helped them understand the concept of safety culture better which in-turn would help them better assess the safety culture of a food business:

332 "I found this was quite useful because it does enable you to categorize the culture 333 based on the attitude in the food business. I was impressed. I thought the culture 334 definitions were very useful." (Environmental Health Officer) 
336 Participants felt that an advantage of using the toolkit was that it would help address

337 the root cause behind an issue instead of waiting for the issue to escalate leading to 338 closures or a low hygiene rating score. They preferred a proactive approach to the reactive approach that is currently used. A proactive approach would help in the long run as if an issue was dealt with at a much earlier stage, not only would the time taken to carry out future inspections reduce, but also there would be a reduction in the number of legal notices served:

"It's trying to seek out the root, the underlying potential to cause... which is important because ... a lot of our work is quite reactive and as a consequence it deals with the issue at hand but not the underlying cause of that issue ..." (Environmental Health 346 Officer)

\subsubsection{Negative responses to the toolkit}

348 Three consistent problems or weaknesses were identified in terms of using the 349 toolkit: (1) length of the document; (2) repetitive nature of Level 2 in the document; and, (3) complicated titles used in the categorization section.

\subsubsection{Length of the document and time constraints}

352 Quite a few of the participants had concerns with the document being too 'wordy'. 353 The problem was interpreted within the context of wider changes within the UK - (1) 354 there have been provincial budget cuts in the UK due to which the number of 355 Environmental Health Officers (EHOs) have been reduced; (2) there is an increase in 356 the number of food businesses which EHOs have to inspect; and, (3) EHOs deal with other departments too such as Health and Safety, housing, environment and noise pollution. Due to this, EHOs were under time constraints. Hence, they felt that in addition to current food hygiene inspection tools (e.g., HACCP, Food Hygiene 360 Rating Scheme, Food Safety Management System), if they were made to use a 361 thirty-two-page long document, they would not be able to do an efficient job and complete inspection targets that had been set by their managers: 
"I think a 32-page document would take quite a long time to do as an add-on to the inspection... it breaks it down into so many different categories and then you look at each one quite specifically..." (Environmental Health Officer)

"There's quite a lot to it...it looks quite complicated when we are already very stretched on food inspections. We are also under pressure to do them as quick as possible ..." (Environmental Health Officer)

Most of them suggested that they would prefer to use a toolkit that could be merged with existing food safety evaluation systems such as the Food Safety Management System (FSMS) or the UK Food Hygiene Rating Scheme:

"I would like the toolkit to be effectively combined with the Food Hygiene Rating 374 Scheme or FSMS to make it less intense. This document (the toolkit) would be 375 easier if it could be integrated into annex 5 [of EC Regulation 852/2004]." 376 (Environmental Health Officer)

\subsubsection{Repetitive nature of the toolkit and over-classification}

Participants felt that the toolkit was quite repetitive and since they already had limited time to inspect premises, they would not have the time to go through a repetitive document. Six of the participants felt that Level 2 of the document could be merged with Level 1 in order to make the toolkit non-repetitive:

"You need a certain amount of time to go through it. Considering inspections these days, many would not have the time to go into Level 2 especially as Level 2 is pretty much a repetition of Level 1." (Environmental Health Officer)

The categorization section has five different categories. This was a cause for worry among the participants as they felt that most food businesses could only be categorized into one of three categories: (1) non-compliers, (2) pro-active compliers and (3) leaders. They felt that the other titles were unnecessary and made classifying businesses more complicated. Another reason for worry was that if there were more options to classify a business, each food inspector would have his/her own classification for a business based on their judgement and this could lead to the 
"It would be the middle categories ... one would err one way while one would err another depending on experience and the type of people they're used to dealing with as well." (Health and Safety advisor, ex-EHO)

400

"Five is too many, you are either non-compliant, half-and-half or fully compliant. I 402 think you only need three... giving it more grading loses the fact that you're either compliant or you're not."' (Food service and environment safety manager)

404

405

3.2.2.3. Small versus large businesses and 'micro-cultures'

406 There are small food businesses that want to improve the safety culture in their businesses but are unable to do so either due to financial constraints or due to having employed temporary staff, thereby making it difficult to instil the business' safety culture in them:

"The smaller businesses, I'm not sure if they're calculative because a lot of them... don't have the money to comply and their attitude is driven by that rather than anything else." (Environmental Health Officer)

413 The 'diversity' factor would have a telling effect on small food businesses such as 414 take-away restaurants, which in addition to employing ethnically diverse personnel 415 also employ part-time staff. Hence, it would be tougher for such businesses to set a 416 pre-defined culture and individual cultures depending on ethnic backgrounds would 417 set in:

418 “... What I call the small business owners, which employ less than ten (full time) 419 people and are owner managed, they have not got the money to spend on food 420 safety expertise and then the culture is quite individual to that particular premise." 421 (Consultant food inspector)

422 Medium and large-scale food businesses consist of many departments, each dealing 423 with various aspects of the food business (e.g., production, packaging, cleaning and 424 transport). During routine inspections, enforcement officers evaluated these various 425 departments in a business and found each section to have a different food hygiene 426 result: 
428 "I think my first impression was a little bit of a worry and a concern that we were 429 trying to pigeon-hole businesses into one category and that might lead you down the 430 wrong route by trying to categorise them into the compliers they are." (Environmental 431 Health Officer)

432

433 Participants were concerned about categorizing businesses as a whole as they felt 434 that a business comprised of many smaller units and sections, each of which had its 435 own culture:

"Being able to state what category they belong to is quite difficult because in some 438 areas they might be brilliant, others, they might not be so good ... you can have 439 certain aspects of a business that are much better than other aspects of a business." 440 (Academic)

\subsection{Other considerations}

443 Participants felt that experience would help food inspectors judge the food safety 444 culture in a food business. When experienced food safety inspectors visit a premise, 445 they are able to make instinctive judgements (as mentioned in 3.1.1.) due to the 446 years of experience they have in inspecting businesses. However, some participants 447 felt that years of experience could make food inspectors overlook certain aspects of 448 culture while new food inspectors would bring in new techniques and new 'angles' in 449 assessing the safety culture of a business. Hence, there should be a combination of 450 new as well as experienced food inspectors while evaluating the safety culture of a food business in order to get a holistic view:

452 "A fresh EHO could bring something new; an old one could miss something as well. 453 So it could be that a mixture of both could be beneficial as this could help get the 454 best out of the service provided, thereby making food businesses safe." (Head of 455 Catering)

\subsection{Improvement suggestions}

458 The encouraging aspect of this study was that although participants had issues with 459 the current version of the toolkit, they understood the importance of a positive safety 
460 culture in a food business and the link between positive safety culture and food 461 safety. In addition to the points mentioned in section 3.2.2., participants also 462 suggested the following improvements to the toolkit to make it practical to use.

463

464 3.4.1. Complexity of the language in the toolkit

465 Stakeholders suggested that a practical toolkit would be only a page long reference 466 tool. They also suggested pictorial representations or simple English for food 467 business owners and food inspectors who were not eloquent in English:

468

469

"You could have a text document or you could have it pictorial, depends. Depends 470 which market you are aiming at. ... I would have text but if English isn't your first language, [then I would like it to be] pictorial." (Head of Catering)

473 Participants felt that the toolkit in its current state was too wordy:

474 “... I would try to plain English it a bit more. I do sometimes find that official 475 documents can get a bit wordy ..." (Environmental Health Officer)

\subsubsection{Inclusion of an anonymous section for employees' opinions}

Participants felt that it was essential to get employees' views on the culture within a food business and how they perceived the management's attitudes and behaviours towards them. However, the drawback here is that only businesses with full-time staff would be able to get their employees to participate, as it would be impossible to inculcate a business' culture in part-time employees:

"It is extremely important to get the employees' views on what they perceive the 485 company wants them to follow with regards to safety. They tend to fill these questionnaires out honestly in order to voice themselves." (Director of Food Safety and Health and Safety)

3.4.3. Paper versus electronic versions of the toolkit

490 Although a few participants expressed their preference for an online document over 491 a text document, one of the participants highlighted the fact that in some food 492 businesses, technology was not allowed on site, even for food inspectors. In such a 493 scenario, it would not be practical for food inspectors to use an online toolkit. Even 
494 food inspectors who chose to use an online toolkit wanted a text document that they 495 could use in the office. Hence, it might be ideal to develop a text as well as an online 496 version of the document:

“... if you go to certain business walk around with your mobile phone, they give you a 499 red card. If you're caught doing it multiple times, you can be in quite a lot of trouble. 500 So I am not sure whether an app would work ..." (Academic)

501

502

“... I would prefer a text document or like an online site where you can fix different 503 bits. It would be ideal if there was a version where I had an option to choose from 504 either ..." (Food and Beverage manager)

505

\section{4. Discussion}

507 4.1. Summary of findings

508 The findings from interviewing Environmental Health Officers (EHOs), Food and 509 Beverage Managers and Academics are summarized in Table 5 in terms of 510 challenges, barriers and future opportunities of safety culture in the food industry.

511 Table 6 summarized the strengths and weaknesses of the toolkit.

\section{$515 \quad 4.2$ The value of food safety culture}

516 Most of the stakeholders interviewed felt that culture had an important role to play

517 with regard to food safety and hygiene and felt that there was a complex interaction 518 between the two - having a positive safety culture would lead to food safety and 519 hygiene. With frequent budget cuts by the government and the number of food 520 businesses constantly on the rise, the already under-pressure EHOs felt that they 521 would not be able to do justice to additional evaluation. Due to the length of the 522 toolkit, they feared that there would be a lack in efficiency and this would lead to an 523 increase in the number of food-borne illnesses and deaths. This is also a view 
524 shared by the report of a recent investigation (Tombs, 2016). The study showed that

525 the number of inspections carried out by food inspectors in the UK had decreased 526 significantly over the last ten years and this could lead to potential public health 527 concerns due to an increased risk of food-borne illnesses and outbreaks. Although 528 Food and Beverage managers were more open towards using a toolkit to evaluate 529 safety culture, they only wanted to assess these evaluations either once a year or 530 quarterly, in the form of audits, and then design a plan accordingly.

\subsection{Integrating food safety culture with other ways of working}

532 Food and Beverage managers preferred using a condensed toolkit. EHOs were not 533 as welcoming to the idea of assessing safety culture in every business they 534 inspected and preferred the toolkit to be merged with existing evaluation tools such 535 as the Food Safety Management System or the Food Hygiene Rating Scheme. The 536 positive here was that all stakeholders appreciated the importance of adopting a 537 proactive approach towards safety culture in food businesses. They felt that adopting 538 such an approach would reduce the number of legal notices and the time taken to 539 carry out inspections as changing the safety culture would improve the approach 540 towards food safety as well as health and safety. The effectiveness of a condensed 541 tool can also be seen from the case where one of the participants had used a similar 542 tool to assess occupational safety culture and felt that the one-page tool that they 543 used was quite effective, time saving and reliable.

$544 \quad$ 4.4 The diversity of food safety cultures

545 Food industries being complex organisations comprising of multiple units, each with 546 its own culture (Antonsen, 2009), it would be challenging to develop a tool/toolkit that 547 could effectively evaluate all the diverse cultures across the business. In addition to 548 this, it would also be challenging to develop a 'one-size-fits-all' toolkit that could 549 effectively assess takeaways, small and medium-large scale businesses. Another 550 challenge would be to evaluate safety culture in businesses that employ 551 casual/temporary workers as these workers do not work in one business/site for long, 552 and would hence fail to understand the culture of the food business. A 553 comprehensive yet effective toolkit with softer user-friendly language would be 554 paramount in the new toolkit. The toolkit was easy to comprehend and use until 555 Level 1 however, when they crossed over to the next level of the toolkit, they found it 
556 to be repetitive and time consuming as the presence of many 'unwanted levels' 557 made the document overly complicated.

558 EHOs and Food and Beverage managers felt that assessing safety culture was an 559 implicit part of their routine inspections. As inspectors' experience and instincts aid in 560 evaluating safety culture, it is essential to include this element in the toolkit. However, 561 since new or relatively new food inspectors would also use the toolkit, it would have 562 to cater to their needs too. Since they (new food inspectors) have no practical 563 experience, it would be advisable to include a guidance section to aid them in 564 evaluating safety culture in the food business.

5654.5 Food safety culture is a 'moving target'

566 The safety culture of any business changes over time. Hence, in order to assess it 567 accurately, it is important to examine the changes in safety culture regularly (Health 568 and Safety Executive, 2005; Jespersen and Huffman, 2014; Waterson and Kolose, 2010). Sustainability of safety culture in businesses is essential for a positive change in human and organizational behaviour to take place. According to the UK Chartered

571 Institute of Occupational Safety and Health (IOSH) (2015), a positive safety culture 572 has three key elements: (1) rules for effectively controlling hazards; (2) a positive 573 attitude towards risk management; and, (3) the capacity to learn from accidents, near 574 misses and safety performance indicators. All these guidelines and indicators are set 575 out at the management level in an organization. It is the role of the senior managers 576 to motivate employees to adhere to these guidelines and promote a positive safety 577 culture (IOSH, 2015).

\section{5. Conclusions, limitations and future work}

579 As seen from this study, stakeholders valued the importance of 'food safety culture' 580 and were aware of the risks of degradation in safety culture even in 'mature' 581 organisations. They understood the benefits of assessing safety culture in food 582 businesses and had various thoughts on what the factors were that were to be 583 measured and how to measure them. Assessing safety culture in some guise or 584 other can prove to be useful as it provides valuable insights when used appropriately 585 (Ackroyd, 2008). However, there are also a few challenges with attempting to 586 measure error and safety culture due to the various characteristics of food 
businesses. Food businesses are complex sociotechnical systems as seen from the study by Nayak and Waterson (2016). Although processes may appear to be simple

589 (e.g., beef production), they go through many steps (e.g., health screening of cows, 590 cleaning, processing, packaging and transportation) and involve a large range of 591 care-processes (e.g., prevention of cross-contamination, working under sterile 592 conditions, temperature control, regular change of clothing, using gloves) 593 (Pennington, 2014). Food safety culture would vary based on the "characteristics of 594 the work tasks, locations, people involved, etc." (Waterson, 2014, p.372). Different 595 roles and types of food businesses will call for different attitudes towards safety, 596 making the measurement of food safety culture more exclusive and difficult. Quite 597 often, safety culture and safety climate are used interchangeably as the latter is a 598 distinct yet related concept (Edwards et al., 2013 and Gadd and Collins, 2002). It is 599 essential that a safety culture tool assess safety culture and not the safety climate of 600 a food business.

601 The current FSA toolkit limits its set of participants to managers and food business 602 operators. It does not involve communication with or feedback from employees 603 working on the factory floor. In order to carry out a detailed analysis of the safety 604 culture in the food business, it is important to make sure that none of the business 605 stakeholders is under-represented. The new toolkit should be able to get the 606 employees' understanding of safety culture and their views on the food business' 607 views on safety culture. This could either be done by personnel using the toolkit 608 speaking to the employees or by employees filling out a questionnaire. It is also 609 important to keep in mind that food businesses are very different from each other. 610 Their operational functioning may vary a great deal across businesses (e.g., small 611 and large-scale businesses); also, "staff may have different attitudes towards safety" 612 (Waterson, 2014, p.374) based on their roles (e.g., permanent and temporary staff). 613 Hence, surveys and toolkits would need to be tailored and modified in line with the 614 type of business.

615 Although the intentions of toolkits (online or text-documents) and questionnaires are 616 to aid process industries to assess key aspects of their safety culture to identify 617 improvements, there are quite a few potential limitations (e.g., internal anchoring and 618 not having an action plan in place due to using the toolkit or questionnaire just as a 619 measurement tool). The challenge facing safety culture assessment tools is to make 
620 sure that they aid improvement and not unwittingly lead organisations astray 621 (Ackroyd, 2008). If not designed and used properly, they can be positively 622 misleading and the dangers of this could be even more harmful than not using these 623 tools, as food businesses would unwittingly have a false sense of self-belief in their 624 safety cultures. Questionnaires, surveys and other tools evaluating attitudes should 625 not solely be used on acceptable/unacceptable basis as responses could be based 626 on issues affecting staff within the food business (e.g., pay, work conditions, attitude 627 of line-managers). This would limit their ability to be used as an absolute measure of 628 performance. Results from these tools must be used to complement insights gained 629 from other safety performance measures such as the Food Safety Management 630 Systems or the Food Hygiene Rating Scheme. If used in combination, they can 631 reveal hidden issues which otherwise may be missed.

632 The biggest limitation of Food and Beverage managers assessing safety culture in 633 the food businesses they work in is 'internal anchoring'. In the nuclear industry, such 634 form of evaluation has shown that although internal staff judge things to be 635 acceptable, peers from outside the organisation had different judgement standards. 636 (Ackroyd, 2008). Internal anchoring is high in industries that are relatively insular and 637 for such businesses, getting an external perspective would be useful. In the food 638 industry, this could be the case with small-scale food businesses or businesses 639 where food safety and health and safety are not given much importance.

640 In addition to using toolkits and questionnaires, other concepts such as 'safety 641 intelligence' also offer potential to better food safety culture analysis. This concept is 642 built on the foundation that senior managers have an influence on organisational 643 safety, which in-turn impacts the safety culture of a business. Safety intelligence 644 relates to the ability of senior managers to develop and enact safety policies (Fruhen, 645 et al., 2014). As not much work has been done in food safety culture, much needs to 646 be learnt from past work within safety-critical industries as there is potential which is 647 yet unrealised.

648 There is a vast sea of opportunities in developing a safety culture analysis tool in the 649 food industry as can be seen from this study. The challenge would be to make this 650 tool a small addition to existing evaluation tools such as the Food Hygiene Rating 651 Scheme (FHRS) or the confidence management systems. Another system that was 
652 recommended was the Kaizen tool as it covers all areas that needed to be evaluated 653 in order to assess culture. Any tool/toolkit developed would have to be 654 comprehensive, effective and easy to use for the benefit of the food businesses as 655 well as food inspectors.

656 Word count: 6,492 (excl. tables and figures)

657

658

659

660

661

662

663

664

665

666

667

668

669

670

671

672

673

674

675 


\section{References}

677

678

679

680

681

682

683

684

685

686

687

688

689

690

691

692

693

694

695

696

697

698

699

700

701

702

703

704

705

706

707

708

709

710

711

Ackroyd, P. (2008). A Safety Culture Toolkit - and Key Lessons Learned. ACS Symposium Series. Retrieved from https://www.icheme.org/communities/subject groups/safety and loss prevention/resources/hazards archive/ /media/Documents/Subject Groups/Safety Loss Prevention/Hazards Archive/XX/XX-Paper-64.pdf

Antonsen, S. (2009). Safety Culture Assessment: A Mission Impossible? Journal of Contingencies and Crisis Management, 17(4), 242-254.

Bona, E., Costa Dias, M. A., Sant'Ana, A. S., Cruz, A. G., Faria, J., \& Fernandes de Oliveira, C. A. (2012). On the implementation of good manufacturing practices in a small processing unity of mozzarella cheese in Brazil. Food Control, 199-205. Retrieved from http://ac.els-cdn.com/S0956713511003999/1-s2.0S0956713511003999-main.pdf? tid=cbba5dfa-7203-11e6-a3f500000aabOf02\&acdnat=1472927311 73d1d91a24942822380f1ed45c8046c3

Branford, K. (2011). Seeing the Big Picture of Mishaps. Aviation Psychology and Applied Human Factors, 1(1), 31-37.

Braun, V., \& Clarke, V. (2006). Using thematic analysis in psychology. Qualitative Research in Psychology, 3(2), 77-101.

Cassano-Piche, A. L., Vicente, K. J., \& Jamieson, G. A. (2009). A test of Rasmussen's risk management framework in the food safety domain: BSE in the UK. Theoretical Issues in Ergonomics Science, 10(4), 283-304.

Cooper, M. D. (2000). Towards a model of Safety Culture. Safety Science, 36, 111136.

Da Cunha, D. T., Stedefeldt, E., and de Rosso, V. V. (2014). The role of theoretical food safety training on Brazilian food handlers' knowledge, attitude and practice. Food Control, 43, 167-174.

Edwards, J. R. D., Davey, J., and Armstrong, K. (2013). Returning to the roots of culture: A review and re-conceptualisation of safety culture. Safety Science, 55, 70-80.

Flick, U. (2014). Interviews. In K. Metzler (Ed.), An Introduction to Qualitative Research (5th ed., pp. 208-241). London: SAGE Publications Ltd.

Flick, U. (2014). Thematic Coding and Content Analysis. In K. Metzler (Ed.), An Introduction to Qualitative Research2 (5th ed., pp. 421-438). London: SAGE Publications Ltd.

Food Standards Agency. (2013). A tool to diagnose cultures in food business operators (FBOs). Retrieved May 11, 2016, from 
Fruhen, L. S., Mearns, K. J., Flin, R., and Kirwan, B. (2014). Safety intelligence: An exploration of senior managers' characteristics. Applied Ergonomics, 45(4), 967-975. Retrieved from http://ac.els-cdn.com/S0003687013002652/1-s2.0S0003687013002652-main.pdf? tid=a025f0dc-3301-11e6-b99f$\underline{00000 a a c b 360 a n d a c d n a t=1465999455}$ 5910e4d4abac7cb5dfaaf9e39adae753

Gadd, S., \& Collins, A. M. (2002). Safety Culture: A review of the literature. Health \& Safety Laboratory. Sheffield.

Greenstreet Berman. (2012). A Tool to Diagnose Culture in Food Business Operators, for the Food Standards Agency. Retrieved May 14, 2016, from http://greenstreet.co.uk/project/a-tool-to-diagnose-culture-in-food-businessoperators-for-the-food-standards-agency-2012l

Griffith, C. J. (2000). Food Safety in Catering Establishments. In J. Farber and E. Todd (Eds.), Safe handling of foods (pp. 235-256). New York: Marcel Dekker.

Griffith, C. J. (2010). Do businesses get the food poisoning they deserve?: The importance of food safety culture. British Food Journal, 112, 416-425.

Griffith, C. J., Livesey, K. M., and Clayton, D. (2010). The assessment of food safety culture. British Food Journal, 112(4), 439-456.

Griffith, C. J., Livesey, K. M., and Clayton, D. A. (2010). Food safety culture: the evolution of an emerging risk factor? British Food Journal, 112, 426-438.

Health and Safety Executive. (2005). A review of safety culture and safety climate literature for the development of the safety culture inspection toolkit. HSE Books. Bristol. Retrieved from http://www.hse.gov.uk/research/rrpdf/rr367.pdf

IOSH. (2015). Promoting a positive culture. The Institution of Occupational Safety and Health. Retrieved from http://www.iosh.co.uk/ /media/Documents/Books and resources/Guidance and tools/Promoting a positive culture.pdf

Institute for Employment Studies, and Cardiff Work Environment Research Centre. (2010). Evidence Review on Regulation Culture and Behaviours.

International Atomic Energy Agency. (2002). Self-assessment of safety culture in nuclear installations. Highlights and good practices. Vienna.

Jespersen, L., and Huffman, R. (2014). Building food safety into the company culture: a look at Maple Leaf Foods. Perspectives in Public Health, 134(4), 200-205.

McKay, F. H., Singh, A., Singh, S., Good, S., \& Osborne, R. H. (2016). Street vendors in Patna, India: Understanding the socio-economic profile, livelihood and hygiene practices. Food Control, 70, 281-285. Retrieved from http://ac.elscdn.com/S0956713516303061/1-s2.0-S0956713516303061- 


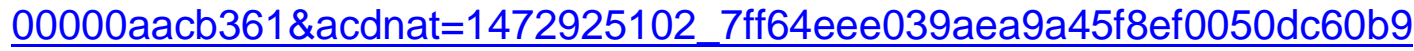

751

752

753

754

755

756

757

758

759

760

761

762

763

764

765

766

767

768

769

770

771

772

773

774

775

776

777

778

779

780

781

782

783

784

785

786

Mearns, K., Whitaker, S. M., and Flin, R. (2003). Safety climate, safety management practice and safety performance in offshore environments. Safety Science, $41(8), 641-680$.

Morse, J. (2004). Purposive Sampling. In M. Lewis-Beck, A. Bryman, and T. Liao (Eds.), The SAGE Encyclopedia of Social Science Research Methods (p.885). Thousand Oaks: SAGE Publications, Inc. Retrieved from http://sk.sagepub.com/reference/download/socialscience/n774.pdf

Nayak, R., and Waterson, P. (2016). "When Food Kills": A socio-technical systems analysis of the UK Pennington 1996 and 2005 E.coli O157 Outbreak reports. Safety Science, 86, 36-47.

Pennington, T. H. (2014). E.coli O157 outbreaks in the United Kingdom: past, present, and future. Infection and Drug Resistance, 7, 211-222.

Salmon, P. M., Read, G. J. M., Stanton, N. A., and Lenné, M. G. (2013). The crash at Kerang: Investigating systemic and psychological factors leading to unintentional non-compliance at rail level crossings. Accident Analysis and Prevention, 50, 1278-1288.

Samapundo, S., Cam Thanh, T. N., Xhaferi, R., \& Devlieghere, F. (2016). Food safety knowledge, attitudes and practices of street food vendors and consumers in Ho Chi Minh city, Vietnam. Food Control, 70, 79-89. Retrieved from http://ac.els-cdn.com/S0956713516302717/1-s2.0-S0956713516302717main.pdf? tid=8aebe6c0-71fb-11e6-bafd00000aab0f02\&acdnat=1472923766 28a31a7b8e4257bea46820194350f043

Sani, N., and Siow, O. N. (2014). Knowledge, attitudes and practices of food handlers on food safety in food service operations at the Universiti Kebangsaan Malaysia. Food Control, 37(1), 210-217.

Sarter, G., and Sarter, S. (2012). Promoting a culture of food safety to improve hygiene in small restaurants in Madagascar. Food Control, 25(1), 165-171.

Stanwell-Smith, R. (2013). Just desserts from our poor food safety culture? Perspectives in Public Health, 133(6), 282. Retrieved from http://www.ncbi.nlm.nih.gov/pubmed/24214999

Taylor, J. (2011). An exploration of food safety culture in a multi-cultural environment: next steps? Worldwide Hospitality and Tourism Themes, 3(5), 455-466.

The Federation of Specialist Restaurants. (2015). Statistics and Data. Retrieved June 20, 2016, from http://www.fedrest.com/marketresearch.htm

Tombs, S. (2016). "Better Regulation": Better for whom ? London. Retrieved from http://www.crimeandjustice.org.uk/publications/better-regulation-better-whom 
787 Vicente, K. J., \& Christoffersen, K. (2006). outbreak: a test of Rasmussen's 788 framework for risk management in a dynamic society. Theoretical Issues in 789 Ergonomics Science, 7(2), 93-112.

790 Waterson, P., and Kolose, S. L. (2010). Exploring the social and organisational 791 aspects of human factors integration: A framework and case study. Safety 792 Science, 48(4), 482-490.

793 Waterson, P. E. (2014). The Prospects for Patient Safety Culture. In P. E. Waterson 794 (Ed.), Patient Safety Culture (1st ed., pp. 371 - 380). Surrey: Ashgate $795 \quad$ Publishing Limited. 
Figure 1: Titles of the elements in the toolkit

Business priorities and attitudes towards food hygiene

Business's perception and knowledge of food safety hazards

Business's confidence in food hygiene requirements

Business ownership of food safety and hygiene

Competence, learning and training in food safety and hygiene systems

Leadership provided on food safety and hygiene

Employee engagement in review \& development of food hygiene practices

Communications \& trust to engage in food safety and hygiene \& report issues 
Table 1: Titles of the categories in the toolkit

Title

Calculative non-compliers

Doubting compliers

Dependant compliers

Proactive compliers

Leaders

\section{Description}

Businesses that intentionally breach regulations for financial gain, without taking into account the potential impact on consumers.

Businesses that have the ability to understand the requirements for food safety and hygiene but fail to understand its importance as they doubt the risk Businesses that rely on third parties to make improvements. They wait for advice or instructions from third parties and do not act on their own.

Businesses that understand the hazards posed by poor food hygiene and wish to ensure effective food safety controls by positively debating on how best to manage food safety hazards.

View food safety and hygiene as critical business issues. 
Table 2: An outline of the Food Standards Agency toolkit developed to assess safety culture in food businesses

\begin{tabular}{|c|c|c|c|}
\hline Section title & Section contents & Elucidation of contents & $\begin{array}{c}\text { Number of } \\
\text { pages }\end{array}$ \\
\hline Introduction & $\begin{array}{l}\text { Application } \\
\text { Purpose of tool } \\
\text { Understanding of food safety culture } \\
\text { Improving food safety culture }\end{array}$ & $\begin{array}{l}\text { An introduction to the general intent of the toolkit and where it } \\
\text { can be used } \\
\text { Uses of the toolkit for inspectors to assess behaviours and } \\
\text { attitudes of businesses towards food safety and hygiene } \\
\text { An outline of the of the toolkit and a general outline on how to } \\
\text { use the toolkit } \\
\text { Relationship between understanding food safety culture and } \\
\text { culture betterment in food businesses }\end{array}$ & 2 \\
\hline Step 1: Categorize food safety culture & $\begin{array}{l}\text { Overview } \\
\text { Level } 1 \text { understanding (Table 1) } \\
\text { Level } 2 \text { understanding (Table 2) }\end{array}$ & $\begin{array}{l}\text { Explanation of Level } 1 \text { and Level } 2 \text { of the toolkit and factors to } \\
\text { consider in order to categorize a food business and use various } \\
\text { sections of the toolkit } \\
\text { Names of the eight categories and meanings of various category } \\
\text { titles } \\
\text { A more detailed analysis: the option of rating each category } \\
\text { based on eight elements and an explanation of how the table is } \\
\text { to be used }\end{array}$ & 3 \\
\hline $\begin{array}{l}\text { Step 2: Guidance on enabling food } \\
\text { safety culture improvement }\end{array}$ & $\begin{array}{l}\text { Table } 3 \\
\text { Table } 4\end{array}$ & $\begin{array}{l}\text { This section contains 'high level' advice that can be given to food } \\
\text { businesses once they are categorized. Table } 3 \text { contains the } \\
\text { 'theme of advice' that 'may be' given to Level } 1 \text { categorized } \\
\text { businesses. } \\
\text { Table } 4 \text { provides 'high level' advice for Level } 2 \text { categorized } \\
\text { businesses. This table has the 'theme of advice' for each } \\
\text { element within the various categories. }\end{array}$ & 8 \\
\hline $\begin{array}{l}\text { Appendix A: Food safety culture } \\
\text { matrix: Element specific descriptions }\end{array}$ & Table 5 & $\begin{array}{l}\text { This section contains Table } 5 \text { which explains what } \\
\text { characteristics food inspectors could look for while assessing } \\
\text { various elements within a category. This is also an advice } \\
\text { section that food inspectors can look at for guidance. There are } \\
\text { pointers for each element per category. }\end{array}$ & 8 \\
\hline $\begin{array}{l}\text { Appendix B: Supporting exploration } \\
\text { and categorization }\end{array}$ & Overview & $\begin{array}{l}\text { This section once again provides an overview of the toolkit and } \\
\text { its purpose. It also explains in short, how to use the various } \\
\text { sections of the toolkit. }\end{array}$ & 4 \\
\hline
\end{tabular}


Table 2: An outline of the Food Standards Agency toolkit developed to assess safety culture in food businesses

\begin{tabular}{|c|c|c|c|c|}
\hline \multirow[t]{2}{*}{ Section title } & \multicolumn{2}{|l|}{ Section contents } & Elucidation of contents & $\begin{array}{c}\text { Number of } \\
\text { pages }\end{array}$ \\
\hline & $\begin{array}{l}\text { Areas to explore } \\
\\
\text { Observations to u } \\
\text { Documents to rev }\end{array}$ & $\begin{array}{l}\text { Priorities and } \\
\text { attitudes } \\
\text { Food hygiene, risk } \\
\text { perception and } \\
\text { knowledge } \\
\text { Confidence in food } \\
\text { hygiene and safety } \\
\text { requirements } \\
\text { Business } \\
\text { ownership of food } \\
\text { hygiene } \\
\text { Competence, } \\
\text { learning, training, } \\
\text { knowledge, etc. } \\
\text { Leadership on food } \\
\text { hygiene } \\
\text { Employee } \\
\text { engagement in } \\
\text { review and } \\
\text { development of } \\
\text { food hygiene } \\
\text { practices } \\
\text { Communication } \\
\text { and trust to engage } \\
\text { in food hygiene and } \\
\text { report issues } \\
\text { lertake } \\
N\end{array}$ & $\begin{array}{l}\text { This section contains possible issues food inspectors could } \\
\text { focus on with regard to each and every element. These are } \\
\text { questions food inspectors could ask themselves (as well as } \\
\text { businesses) when they visit food businesses in order to assess } \\
\text { the safety culture. }\end{array}$ & \\
\hline $\begin{array}{l}\text { Appendix C: Background, purpose } \\
\text { and application of the tool }\end{array}$ & $\begin{array}{l}\text { Background } \\
\text { What is food safe } \\
\text { Purpose of the toc } \\
\text { Application: Unde } \\
\text { culture } \\
\text { Improving food sa }\end{array}$ & $\begin{array}{l}\text { culture? } \\
\text { tanding food safety } \\
\text { ty culture }\end{array}$ & $\begin{array}{l}\text { This section describes why the Food Standards Agency } \\
\text { commissioned a project with the objective of being able to } \\
\text { analyse safety cultures in food businesses. It then further } \\
\text { elucidates the meaning of food safety culture, its importance and } \\
\text { methods of improving safety culture in food businesses. }\end{array}$ & 7 \\
\hline
\end{tabular}


Table 3: Study participants and experience

\begin{tabular}{|c|c|c|}
\hline Sector & $\begin{array}{l}\text { Role [number of } \\
\text { participants] }\end{array}$ & $\begin{array}{l}\text { Experience in current role (years) } \\
\text { Range of experience (years) }\end{array}$ \\
\hline \multirow{4}{*}{ Government } & Environmental & $7-36.5$ \\
\hline & $\begin{array}{l}\text { Health Officers } \\
\text { (General) [13] }\end{array}$ & \\
\hline & $\begin{array}{l}\text { Health and safety } \\
\text { advisor [1] }\end{array}$ & 10 \\
\hline & $\begin{array}{l}\text { Consultant food } \\
\text { inspector [1] }\end{array}$ & 11 \\
\hline \multirow[t]{7}{*}{ Food industry } & $\begin{array}{l}\text { Food service and } \\
\text { environment safety } \\
\text { manager [5] }\end{array}$ & $3-16$ \\
\hline & $\begin{array}{l}\text { Food safety expert } \\
{[1]}\end{array}$ & 0.5 \\
\hline & Food and & $10.5-16$ \\
\hline & $\begin{array}{l}\text { Beverage manager } \\
\text { [2] }\end{array}$ & \\
\hline & $\begin{array}{l}\text { Head of catering } \\
\text { [2] }\end{array}$ & $3-25$ \\
\hline & Director of Food & $9-20$ \\
\hline & $\begin{array}{l}\text { Safety and Health } \\
\text { and Safety [2] }\end{array}$ & \\
\hline \multirow[t]{4}{*}{ Academia } & Lecturer in Food & 4 \\
\hline & Science and & \\
\hline & Technology [1] & \\
\hline & Teaching fellow [2] & $9-15$ \\
\hline
\end{tabular}


Table 4: Coding framework

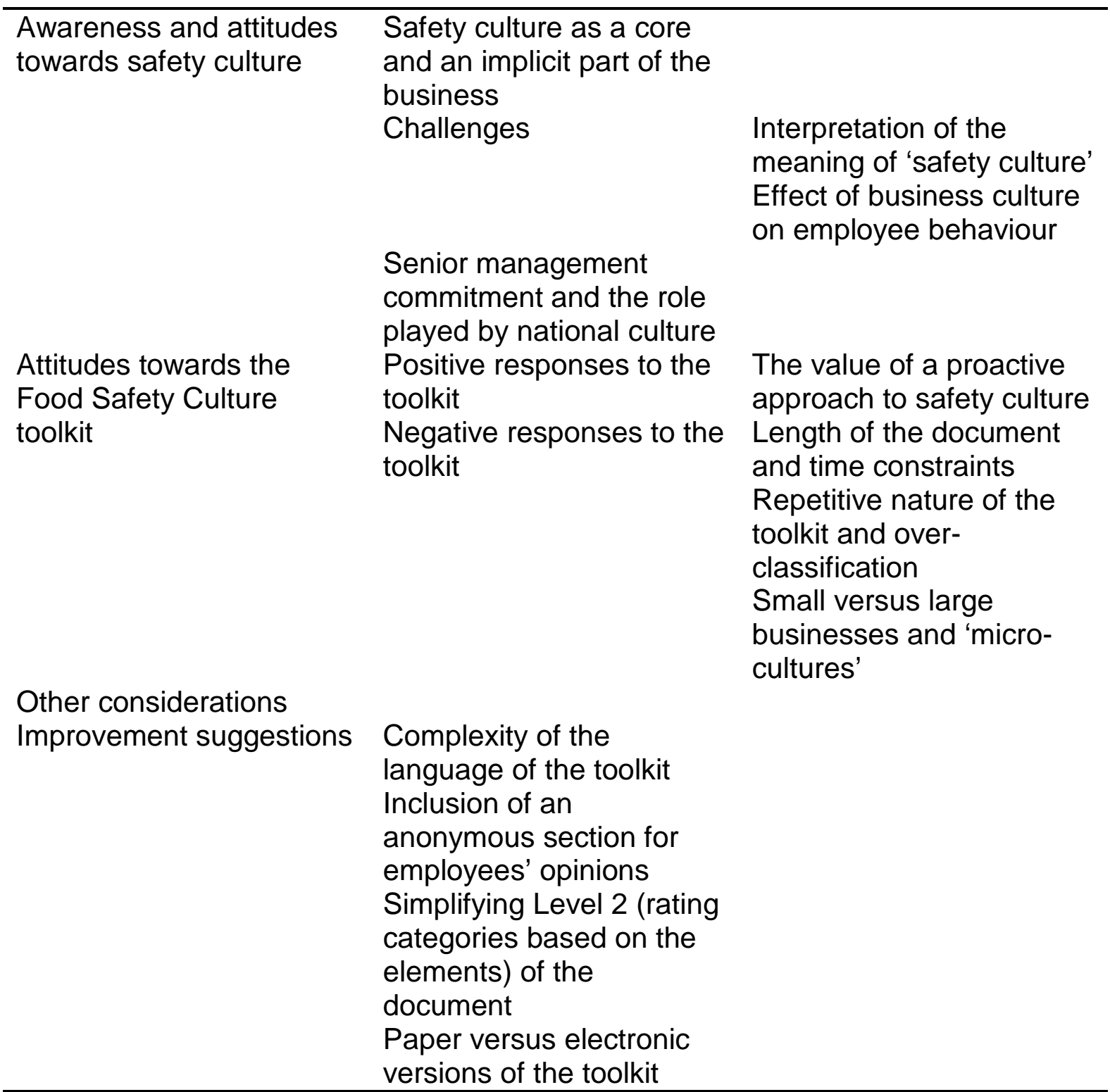


Table 5: Opportunities, barriers and challenges of safety culture in the food industry

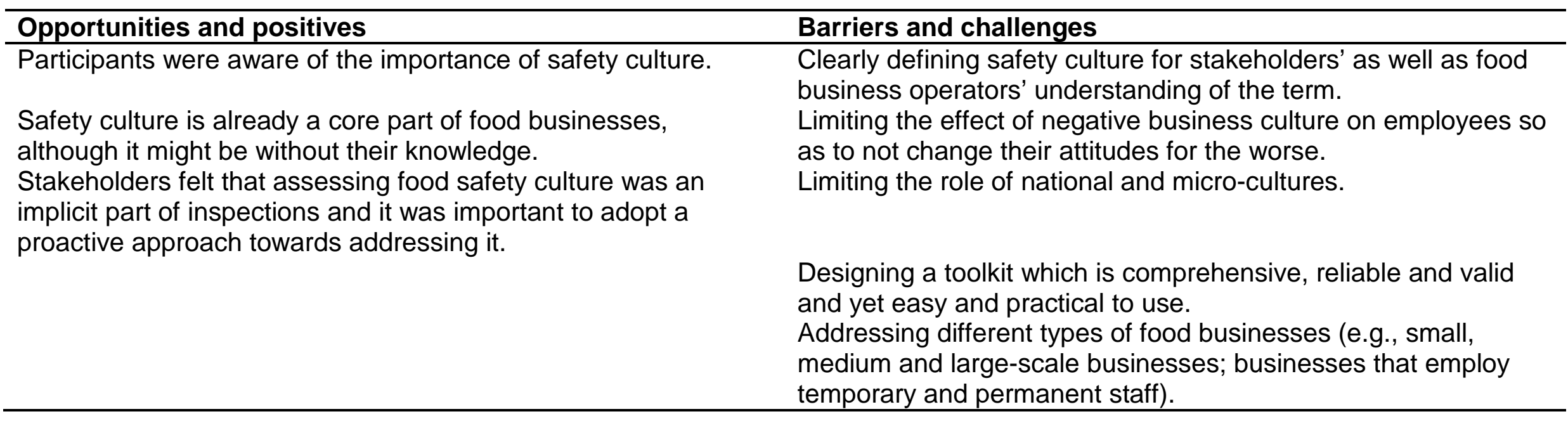


Table 6: Strengths and weaknesses of the FSA toolkit

\begin{tabular}{ll}
\hline Strengths & Weaknesses \\
\hline $\begin{array}{l}\text { Detailed overall analysis of food safety culture in the business. } \\
\text { Makes understanding new concepts (e.g., food safety culture) } \\
\text { easier as they are clearly defined in Appendix C of the toolkit. }\end{array}$ & $\begin{array}{l}\text { Repetitive nature of Level } 2 \text { and length of the toolkit. } \\
\text { Use of complicated titles in the categorization section and } \\
\text { complex language: this would be an even bigger problem for } \\
\text { food inspectors and food business operators whose native } \\
\text { language is not English. }\end{array}$ \\
$\begin{array}{ll}\text { As it is not merged with other existing schemes such as the } \\
\text { Helps in adopting a proactive approach to safety culture. }\end{array}$ & $\begin{array}{l}\text { Food Hygiene Rating Scheme or the Food Safety Management } \\
\text { Systems, it becomes an additional document Environmental }\end{array}$ \\
$\begin{array}{ll}\text { Makes local authority personnel think about the importance of a } \\
\text { positive safety culture in food businesses (once they have read }\end{array}$ & $\begin{array}{l}\text { Inability to assess micro-cultures and differentiate food safety } \\
\text { cultures in food businesses with temporary and permanent staff. }\end{array}$ \\
$\begin{array}{l}\text { Involves communication with management in food businesses, } \\
\text { thereby, helping to understand their commitment to safety and } \\
\text { developing a positive safety culture. }\end{array}$ & $\begin{array}{l}\text { Inability to assess small and large-scale food businesses } \\
\text { differently }\end{array}$ \\
& $\begin{array}{l}\text { No fixed sample size required for carrying out assessments, } \\
\text { especially in large-scale food businesses. }\end{array}$ \\
& $\begin{array}{l}\text { The toolkit is designed primarily for use by local authority } \\
\text { personnel and not for food safety managers. }\end{array}$ \\
\hline
\end{tabular}

